\begin{tabular}{lc}
\hline & Sharif University of Technology \\
SCIENTIA & Transactions B: Mechanical Engineering \\
IRAN ICA & www.scientiairanica.com \\
\hline
\end{tabular}

\title{
Investigation of fluid flow and heat transfer of compressible flow in a constricted microchannel
}

\author{
M.M. Heydari* \\ Aerospace Complex, Malek-Ashtar University of Technology, Tehran, Iran.
}

Received 16 November 2014; received in revised form 22 July 2015; accepted 21 October 2015

\section{KEYWORDS}

Constricted microchannel;

Compressible flow;

Rarefaction;

Convective heat

transfer.

\begin{abstract}
Heat transfer and hydrodynamics of air flow in a constricted microchannel are numerically investigated by considering the effect of geometry, stagnation pressure and temperature at the inlet, and applied heat flux at the walls. Kurganov-Tudmor method is used to solve the governing equation; Maxwell and Smoluchowski approaches are used to model the rarefaction effects of compressible micro flow. This study shows that using slip model is necessary in both high-speed and low-speed flows, especially at the downstream of the constricted portion. Also, throat height reduction results in more rarefaction and compressibility at the constricted region.
\end{abstract}

(C) 2016 Sharif University of Technology. All rights reserved.

\section{Introduction}

With the advance of micro and nano technology, visualization and calculation of physical phenomena in small-scale geometries have been the topic of numerous studies in different fields of science. In the field of Microfluidics, various investigations of compressible gas flow and heat transfer in straight microchannels have been widely investigated. The laminar slip flow thermal entry problem in rectangular microchannels with constant wall heat flux has been analytically studied by a modified integral transform technique by $\mathrm{Yu}$ and Ameel [1]. It was found that heat transfer may increase, decrease, or remain unchanged, compared to the nonslip conditions, subjected to two dimensionless variables $\beta-v \mathrm{Kn}$ and $\beta$, and aspect ratio $\mathrm{R}$. $\beta-$ $v \mathrm{Kn}$ indicates the rarefaction effects or microscale effects and is a measure of the momentum exchange between the fluid and the walls, while $\beta$ represents the properties of fluid/wall interaction and is a measure of the effects of temperature jump near the walls. Asako et al. [2] numerically studied the effect of

*. Tel.: +982166069521

E-mail address: mmheydary@mmut.ac.ir compressibility on gaseous flow in microchannels. They focused on the product of friction factor and Reynolds number $(f R e)$, and found that this value differs from the incompressible value of 96 for parallel-plate ducts. They also found an expression for $f$ Re as a function of Mach number. Miyamoto et al. [3] investigated heat transfer of compressible flow in a microchannel both numerically and experimentally. At first, they found that the mass flow rate in microchannel decreases by increasing heat flux. Then, they considered Nusselt number for compressible flow and found that Nusselt number approaches to fully developed incompressible flow $(\mathrm{Nu}=8.23)$ in the middle section of the microchannel, while the value is different from incompressible flow at the inlet and outlet section. Hong et al. [4] numerically investigated heat transfer characteristics of compressible flow in a microchannel. According to their work, the slip effects at the wall temperature become negligible by increasing compressibility (inletoutlet pressure ratio). In another work, Asako and Toriyama [5] investigated heat transfer characteristics of compressible flow in a microchannel when the walls are at constant temperature. They mainly focused on the change of mean air temperature, microchannel's wall temperature at different channel heights, pressure 
ratios, and heat fluxes, and then compared them with incompressible flow. According to their results, the mean temperature along the channel has a maximum point at the middle section and at the channel's outlet; the bulk temperature decreases as a result of conversion of internal energy into kinetic energy.

In the slip flow regime, the Navier-Stokes equations are still valid together with the modified boundary conditions at the wall [6,7]. $\mathrm{Xu}$ and Zhao [8] (2007) chose the Navier-Stokes equations subject to slip wall boundary conditions and simulated small-scale nozzle flow subject to different back pressures. They studied the shock structures at low Knudsen number flows. They found that the viscous effect would be the key parameter in shock wave formation within the micronozzle.

Chen and Cho [9] investigated the mixing characteristics of flow through microchannels with wavy surfaces. However, they modeled the wavy surface as a series of rectangular steps and it seemed to cause computational errors at boundary, especially in microscale geometry. Also, their working fluid was liquid and they applied no-slip boundary conditions at the microchannel wall surface. Besides, other aspects of heat transfer in wavy micro-channels were studied in $[10-12]$.

Recently, Louisos et al. [13] have reviewed the key findings obtained from computational studies of supersonic micronozzle flow using both continuum and kinetic based techniques. They reported that the combination of viscous, thermal, and rarefaction effects on the microscale flow structure would considerably affect the supersonic flow behavior in micronozzles. They described different aspects of rarefaction effects in nozzle performance.

Lin and Gadepalli [14] investigated the gas flow characteristics in an axisymmetric micronozzle configuration within parameter ranges different from previous studies. They put emphasis on the effect of throat diameter covering a range of macro to micro scales on the nozzle's performance. The nozzle throat diameter was varied from $10 \mathrm{~mm}$ to $0.1 \mathrm{~mm}$; the throat Reynolds number was varied from 5 to 2000 .

Rij et al. [15] investigated the effects of rarefaction, viscous dissipation, compressibility, and axial conduction on the Nusselt number in a rectangular microchannel subject to constant wall heat flux and constant wall temperature. It was shown that rarefaction and viscous dissipation effects significantly affect the convective heat transfer rate in the slip flow regime. They also found that combined effects of viscous dissipation, flow work, and shear work within the slip flow regime cause $\mathrm{Nu}$ to increase in the case of constant wall temperature.

San et al. [16] (2009) studied the size and expansion ratio effects on the micronozzle flow field behavior solving the two-dimensional augmented Burnett and the Navier-Stokes equations. They reported small differences in the solutions of low Knudsen number flows subject to either slip or no-slip boundary conditions. Duryodhan et al. [17] conducted an experimental and three-dimensional numerical study on the heat transfer of a single phase liquid flow in a heated diverging and heated converging microchannel. They found that the heat flux in a converging microchannel is much more uniform as compared with a diverging microchannel, which clearly indicates the stronger conjugate effect in a converging microchannel.

Darbandi and Roohi [18] provided a deeper understanding of the flow behavior in the micro/nanoscale converging-diverging nozzles. They investigated the effects of back pressure, Knudsen number, and gassurface interaction on the nozzle flow behavior by the compressible OpenFOAM solver. Shokouhmand and Bigham [19] analyzed both the hydrodynamic and thermal aspects of a gaseous flow in the constricted microchannels.

Sadeghi et al. [20] investigated the effect of corrugated roughness on the fully developed forced convection of a rarefied gas in a micropipe. They concluded that the pressure drop is an increasing function of the relative roughness.

The gaseous slip flow forced convection in microducts of different cross sections was investigated by Baghani and Sadeghi [21]. Four different cross sections of polygonal, trapezoidal, rhombic, and elliptic shape were considered for presentation, and the tabulated data of Nusselt number were presented for each geometry by covering the entire slip flow range of the Knudsen number.

In another work, Sadeghi et al. [22] studied the gaseous slip flow mixed convection through vertical channels of two different cross sections, namely, polygon, with circle as a limiting case, and rectangle. In their study, the flow was assumed to be fully developed, and both classical thermal boundary conditions of $\mathrm{H} 1$ and $\mathrm{H} 2$ were considered in the analysis. Their analysis revealed that both the Nusselt number and the pressure drop parameter are the increasing functions of the Grash of Reynolds ratio. Whereas an increase in Knudsen number generally gives rise to smaller values of the Nusselt number and the pressure drop, the Knudsen number's functionality of the H2 Nusselt number for the triangular duct is the opposite. Also, Sadeghi and Saidi [23] derived the analytical solutions for laminar forced convection heat transfer of a viscous dissipative gas flow in two micro-geometries, namely, micro-annulus and parallel plate micro-channel. They assumed that the flow is steady and fully developed, both hydrodynamically and thermally. The rarefaction effects were taken into consideration using first-order slip velocity and temperature jump boundary condi- 
tions. They found that viscous heating causes singularities in Nusselt number values. Also, asymmetry causes singularities in Nusselt numbers of both microannulus walls and also the parallel plate wall to have lower heat flux, even in the absence of viscous heating. Mirmanto [24] studied flow boiling heat transfer of de-ionized water in single horizontal microchannels by means of linear pressure gradient method and pressure gradient measurement method to see if the linear pressure gradient assumption is valid for any heat fluxes. He recommended to use pressure gradient when the generated pressure drop is low.

Asadi et al. performed a comprehensive review on the heat transfer and pressure drop characteristics of single and two-phase microchannels that is accessible in [25].

Yari Ghale and Haghshenasfard [26] developed a CFD approach to predict the Nusselt number and friction factor of $\mathrm{Al}_{2} \mathrm{O}_{3}$ /water nanofluids in a straight and ribbed microchannel heat sink. They showed that two-phase model is more precise than the singlephase model by the comparison of numerical results and experimental data. Also, it was found that by increasing the channel width, the heat transfer performance increases; while by increasing the rib height, the thermal performance of the channel decreases.

$\mathrm{Li}$ and Haramura [27] investigated analytically the heat transfer characteristics of the reciprocating laminar flow in a micro-channel type porous-sheets Stirling regenerator, including the entrance effects, to facilitate the efficient design and optimization of Stirling engines. Wand [28] developed an approach using the Ritz method for slip flow and heat convection that can be applied to any tube cross section. This method for slip flow and constant flux heat transfer in ducts of general shape was established and applied to the isosceles triangular duct, yielding tables for the Poiseuille number and the Nusselt numbers. This approach is a boundary fitted method such that curved boundaries and sharp corners do not pose a problem. In addition, the boundary conditions for the slip flow need local normal derivatives, which are difficult to construct for finite difference or finite element schemes. But, according to the current theorems, these mixed boundary conditions are automatically satisfied by the minimization of the functional.

Law and Lee [29] did a comparative study on the heat transfer performance, pressure drop, and instability characteristics in straight-finned and oblique-finned microchannels, and showed that the heat transfer performance of the oblique-finned microchannels is significantly better than its straight-finned counterpart.

Kiyasatfar and Pourmahmoud [30] did an investigation on the fully developed flow and heat transfer of conducting non-Newtonian fluids through square microchannels under the influence of an applied uniform magnetic field, considering effects of viscous dissipation and Joule heating. According to their results and the capability of MPL model in the correctly prediction of apparent viscosity of non-Newtonian fluids in the whole region of shear rate from zero to infinity, they recommended MPL model to be used in similar cases. Pelevi and VanderMeer [31] used the lattice Boltzmann method for the first time to investigate influence of three-dimensional surface roughness on fluid flow and heat transfer phenomena within a microchannel. It was found that the Gauss function is an efficient and convenient method to build the roughness rather than the other models. In addition, they investigated the influence of the roughness cut-off frequencies and the relative roughness height. They concluded that the influence of the roughness cut-off frequency cannot be neglected. Also, it was found that there is a minor effect of the relative roughness on fluid flow and heat transfer phenomena.

Heydari. [32] considered a combined electroosmotic and pressure-driven flow of a viscoelastic fluid through a long rectangular microchannel. The rheological behavior of the fluid is assumed to be represented by either of PTT or FENE-P models. The flow is considered to be steady, laminar, and fully developed. It is assumed that the liquid contains an ideal solution of fully dissociated symmetric salt. Moreover, the channel wall is considered to be subject to a constant zeta potential.

According to the previous work, high-speed compressible flow in a sinuous curved micro channel is not investigated. In this work, the objective is to study the effects of different criteria of pressure ratio, heat flux, and the throat area on the fluid flow regime and thermal characteristics inside the channel. Specifically, the rarefaction, slip condition, and also variable fluid properties are taken into account in this work.

\section{Problem definition}

Schematic of channel geometry is shown in Figure 1. As shown, air with stagnation pressure and temperature of $P_{\text {stg }}$ and $T_{\text {stg }}=300 \mathrm{~K}$ enters the microchannel with the height of $30 \mu \mathrm{m}$ while constant heat flux is applied at the walls. A curved microchannel with a length of $2 H$ is constricted along the plane microchannel. The total length of plane microchannel is $17 \mathrm{H}$ and the outlet

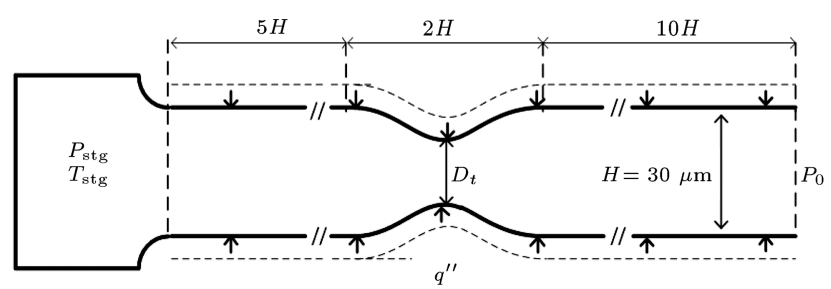

Figure 1. Schematic of the geometry. 
pressure is $P_{0}=100 \mathrm{kPa}$. The zero gradient velocity is applied at outlet and inlet; slip or no-slip condition is applied at the walls depending on the cases in the table. The constricted microchannel profile is a sinusoidal function as follows:

$$
y=\frac{H-D_{t}}{2} \cos \left(\frac{\pi}{2 H}(x-6 H)\right) .
$$

The fluid properties are considered a function of temperature. To do this, Sutherland [33] and modified Euken models [34] are supposed for viscosity and thermal conductivity, respectively:

Sutherland model:

$$
\begin{aligned}
& \mu(T)=\frac{A_{s} \sqrt{T}}{1+\frac{T}{T_{0}}}, \quad T_{0}=110.4, \\
& A_{s}=1.458 \times 10^{-6} .
\end{aligned}
$$

Modified Euken model:

$$
k(T)=\mu(T)\left(1.77 R+1.32 \frac{R}{\gamma-1}\right) .
$$

In our simulations, the change of throat height, pressure ratio, and heat flux at the walls are considered. Different simulation characteristics are listed in Table 1. Since the gas flow is pressure driven, zero gradient condition is applied for the velocity at the inlet and outlet zones. Also, pressure field is subjected to zero gradient condition at the walls. The convergence criterion for the numerical simulation was the minimum residual of $10^{-8}$ for all parameters.

\section{Governing equations}

Governing equations of this study consist of conservation laws of unsteady compressible flow with variable fluid properties. The continuity equation is:

$$
\frac{\partial \rho}{\partial t}+\frac{\partial \rho u}{\partial x}+\frac{\partial \rho v}{\partial y}=0
$$

Conservation of momentum in a $2 \mathrm{D}$ field must be satisfied via:

$$
\left\{\begin{aligned}
\frac{\partial \rho u}{\partial t}+ & \frac{\partial \rho u u}{\partial x}+\frac{\partial \rho v u}{\partial y}=-\frac{\partial P}{\partial x} \\
- & \frac{2}{3} \frac{\partial}{\partial x}\left[\mu\left(\frac{\partial u}{\partial x}+\frac{\partial u}{\partial y}\right)\right]+\frac{\partial}{\partial x}\left[\mu\left(\frac{\partial u}{\partial x}+\frac{\partial v}{\partial y}\right)\right] \\
\frac{\partial \rho u}{\partial t}+ & \frac{\partial \rho u v}{\partial x}+\frac{\partial \rho v v}{\partial y}=-\frac{\partial P}{\partial y} \\
& -\frac{2}{3} \frac{\partial}{\partial y}\left[\mu\left(\frac{\partial v}{\partial x}+\frac{\partial v}{\partial y}\right)\right]+\frac{\partial}{\partial y}\left[\mu\left(\frac{\partial u}{\partial x}+\frac{\partial v}{\partial y}\right)\right]
\end{aligned}\right.
$$

where $\mu$ is the viscosity calculated via Eq. (2). The
Table 1. Throat height, stagnation pressure and temperature, heat flux, and wall boundary condition at the walls.

\begin{tabular}{ccccl}
\hline$\#$ & $\begin{array}{c}\boldsymbol{P}_{\text {stg }} \\
(\mathbf{k P a})\end{array}$ & $\begin{array}{c}\boldsymbol{D} \\
(\boldsymbol{\mu} \mathbf{m})\end{array}$ & $\begin{array}{c}\boldsymbol{q}^{\prime \prime} \\
\left(\mathbf{k W} / \mathbf{m}^{\mathbf{2}}\right)\end{array}$ & Slip/no slip \\
\hline 1 & 110 & 5 & 100 & Slip \\
2 & 120 & 5 & 100 & Slip \\
3 & 130 & 5 & 100 & Slip \\
4 & 140 & 5 & 100 & Slip \\
5 & 150 & 5 & 100 & Slip \\
6 & 110 & 5 & 100 & No slip \\
7 & 120 & 5 & 100 & No slip \\
8 & 130 & 5 & 100 & No slip \\
9 & 140 & 5 & 100 & No slip \\
10 & 150 & 5 & 100 & No slip \\
11 & 150 & 5 & 0 & Slip \\
12 & 150 & 5 & 1 & Slip \\
13 & 150 & 5 & 10 & Slip \\
14 & 150 & 5 & 15 & Slip \\
15 & 150 & 10 & 100 & Slip \\
16 & 150 & 15 & 100 & Slip \\
17 & 150 & 20 & 100 & Slip \\
18 & 150 & 25 & 100 & Slip \\
19 & 150 & 30 & 100 & Slip \\
\hline & & & & \\
\hline
\end{tabular}

energy equation of compressible flow is:

$$
\begin{gathered}
\frac{R}{\gamma-1}\left(\frac{\partial \rho T}{\partial t}+\frac{\partial \rho u T}{\partial x}+\frac{\partial \rho v T}{\partial y}\right)=-P\left(\frac{\partial u}{\partial x}+\frac{\partial v}{\partial y}\right) \\
+\frac{\partial}{\partial x}\left(k \frac{\partial T}{\partial x}\right)+\frac{\partial}{\partial y}\left(k \frac{\partial T}{\partial y}\right)+\emptyset
\end{gathered}
$$

where $k$ is the fluid thermal conductivity. The last term on the right-hand side is viscous dissipation, work done by shear stress forces, which has an important role in our investigation. This term is calculated as below:

$$
\begin{aligned}
\emptyset= & \mu\left\{2\left[\left(\frac{\partial u}{\partial x}\right)^{2}+\left(\frac{\partial v}{\partial y}\right)^{2}\right]-\frac{2}{3}\left(\frac{\partial u}{\partial x}+\frac{\partial v}{\partial y}\right)^{2}\right. \\
& \left.+\left(\frac{\partial u}{\partial y}+\frac{\partial v}{\partial x}\right)^{2}\right\} .
\end{aligned}
$$

The conservation equations are along with the equation of state:

$$
P=\rho R T \text {. }
$$

In order to model the rarefaction effects of gas flow in micro scale, Maxwell model is used:

$$
U_{\text {slip }}-U_{w}=\frac{2-\sigma_{v}}{\sigma_{v}} \frac{1}{\rho \sqrt{\frac{2 R T_{w}}{\pi}}} \tau_{s}+\frac{3}{4} \frac{\operatorname{Pr}(\gamma-1)}{\gamma \rho R T_{w}}\left(-q_{s}\right),
$$

where $U_{\text {slip }}$ and $U_{w}$ are the slip velocity and wall velocity, $\sigma_{v}$ is the accommodation coefficient of momentum, 
and $q_{s}$ is the tangential component of heat flux at the wall. The second term on the right-hand side is the effect of thermal creep on the slip velocity. For temperature field, the rarefaction effect (temperature jump) is calculated by applying Smoluchowski model:

$$
T_{\text {slip }}-T_{w}=\frac{2-\sigma_{T}}{\sigma_{T}}\left(\frac{2(\gamma-1)}{\gamma+1}\right) \frac{1}{R \rho \sqrt{\frac{2 R T_{w}}{\pi}}}\left(-q_{n}\right),
$$

in which $T_{\text {slip }}$ and $T_{w}$ are the slip temperature and wall temperature, $\sigma_{T}$ is the accommodation coefficient of temperature, and $q_{n}$ is the normal component of heat flux at the wall.

In order to solve the governing equations, Kurganov-Tudmor (KT) method is used, which was introduced in 2000 [35]. In this method, a collocated cell is used to solve the field of velocity and pressure; there is no need for Reyman solvers. In addition, KT method is a very stable and relatively simple approach to solve compressible flows. OpenFOAM code is used for applying this method and Crank-Nicholson method is applied for solving the unsteady equations along the time.

\section{Mesh independency and verification}

In this section, the correctness of the numerical code is checked by comparing the results with the previous results. Also, independency of solution from the mesh size is investigated. In order to verify our numerical code, compressible viscous flow in a straight microchannel is calculated and compared with Hong et al.'s work [3]. Compressible air flow in a microchannel with height and length of $10 \mu \mathrm{m}$ and $2000 \mu \mathrm{m}$ is considered while a constant heat flux of $10^{4} \mathrm{~W} / \mathrm{m}^{2}$ is applied at the walls. Air with stagnation temperature and pressure of $300 \mathrm{~K}$ and $400 \mathrm{kPa}$ enters the microchannel while the outlet pressure is $100 \mathrm{kPa}$. According to Figure 2, there is a very good agreement between the results of our code and the results of Hong et al. [4] for a straight channel.

The distribution of Mach number along the curved channel by using different mesh sizes are shown in Figure 3. For this mesh study, the problem condition is analogous with the case 11 in Table 1 . According to these results, the mesh size of $30 \times 200$ has been used in our study.

\section{Results}

\subsection{The effect of pressure ratio}

According to the work of Hong et al. [4], in a plane channel, by increasing pressure ratio, the effect of rarefaction decreases in comparison with compressibility effects. Distribution of Knudsen number is shown in Figure 4. Heat flux of $10^{4} \mathrm{~W} / \mathrm{m}^{2}$ is applied

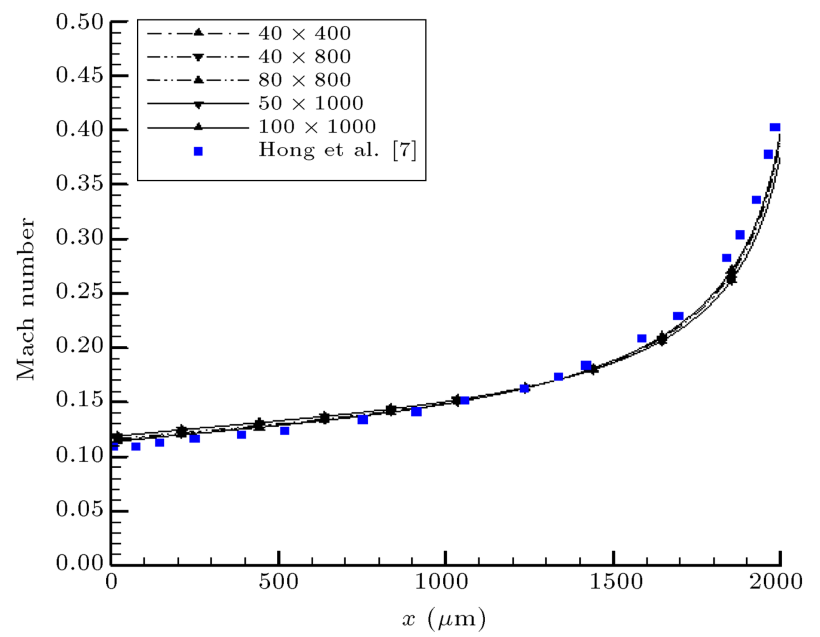

Figure 2. Verification of the code for a straight channel. Different mesh sizes are used for more comparisons.

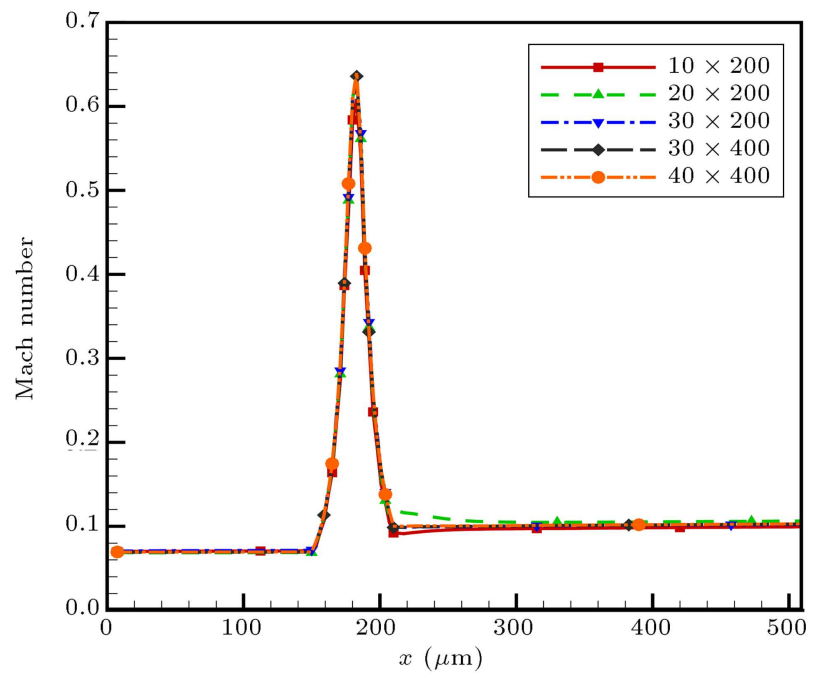

Figure 3. Variation of Mach number along the curved channel for different mesh sizes.

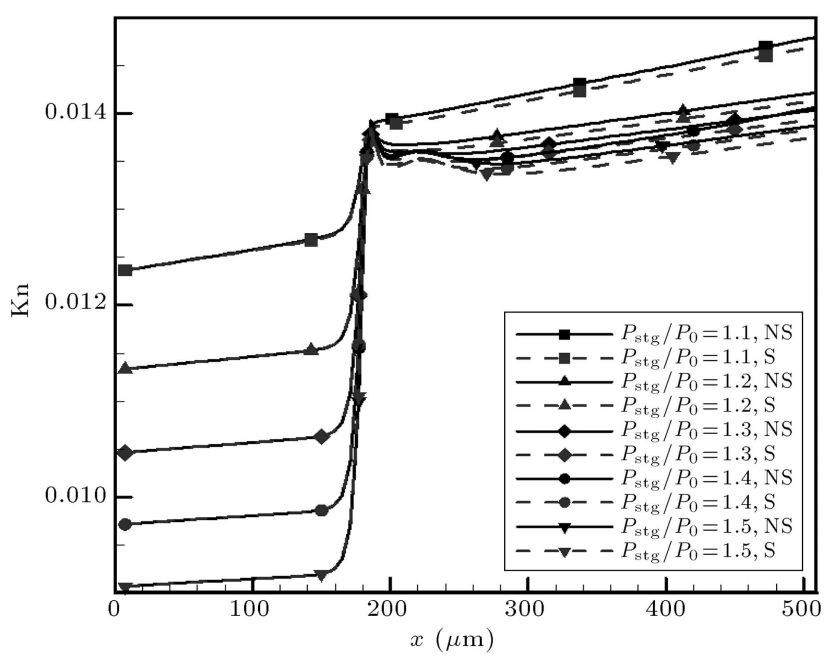

Figure 4. Knudsen number distribution along the micro-channel at different pressure ratios in slip and no slip conditions $\left(D_{t}=5 \mu \mathrm{m}, q^{\prime \prime}=10^{4} \mathrm{~W} / \mathrm{m}^{2}\right)$. 
to the walls and throat height is considered $5 \mu \mathrm{m}$. As shown, at pressure ratio of 1.1 and at the microchannel's upstream $(x<180 \mu \mathrm{m})$, the Knudsen number curves of slip and no-slip conditions are quite similar, and increase monotonically. In the curved portion $(150<x<210 \mu \mathrm{m})$, there is a considerable increase in rarefaction because of raising the Mach number. Finally, at the downstream $(x>210 \mu \mathrm{m})$, the difference between slip and no-slip models appears to be important. In fact, after the curved portion, the density and pressure decrease dramatically which causes increment of rarefaction and in the rarefied regime, we expect to have a sensible difference between slip and no-slip models at the walls.

In order to estimate the compressibility at different pressure ratios, distribution of Mach number along the micro-channel is demonstrated in Figure 5. To show more details of Mach number in a constricted portion, the Mach number curves of this section are magnified. In general, the difference between slip and no-slip models in prediction of compressibility is not sensible. As expected, at pressure ratio of 1.1 , the flow at a constricted region is incompressible. And, when the pressure ratio goes above 1.2 , compressible flow is seen.

After the discussion of rarefaction and compressibility, the non-dimensional surface temperature is considered in Figure 6. According to this figure, at the upstream and before the constricted portion, there is no sensible difference between slip and no-slip models of velocity and temperature at the walls, while considerable distinction appears at the constricted microchannel and its downstream, and it is necessary to use Maxwell and Smoluchowski models for velocity and temperature fields to take into account the effects of rarefied gas flow. Another important point is that using slip model is necessary at every pressure ratio. Also, as the pressure ratio increases, the necessity of slip modeling increases in the constricted channel. Thus, in the subsequent sections, the Maxwell and Smoluchowski models are used in the simulations.

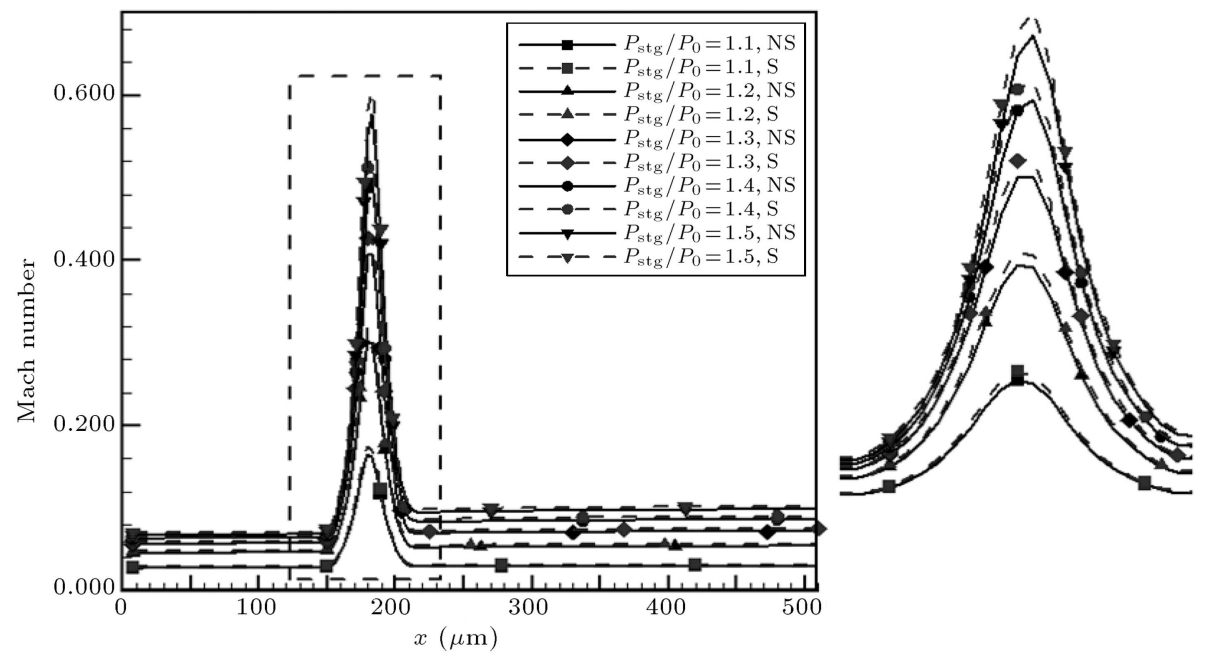

Figure 5. Mach number along the channel at different pressure ratios $\left(D_{t}=5 \mu \mathrm{m}, q^{\prime \prime}=10^{4} \mathrm{~W} / \mathrm{m}^{2}\right)$.

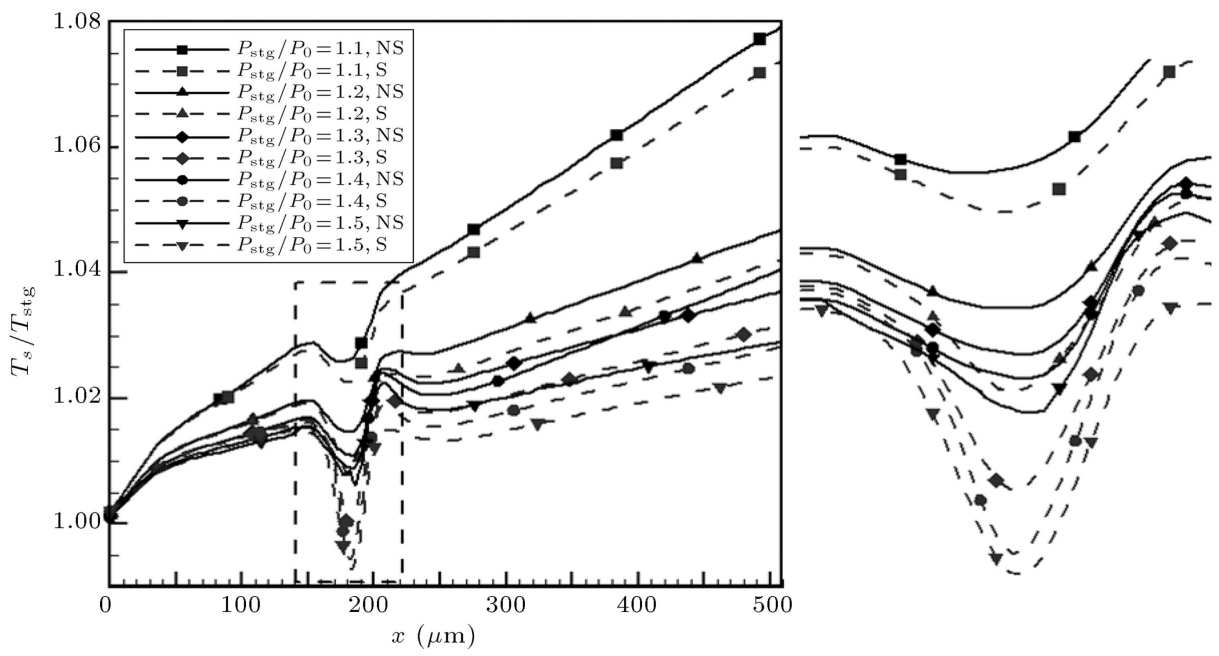

Figure 6. Wall temperature at different pressure ratios $\left(D_{t}=5 \mu \mathrm{m}, q^{\prime \prime}=10^{4} \mathrm{~W} / \mathrm{m}^{2}\right)$. 


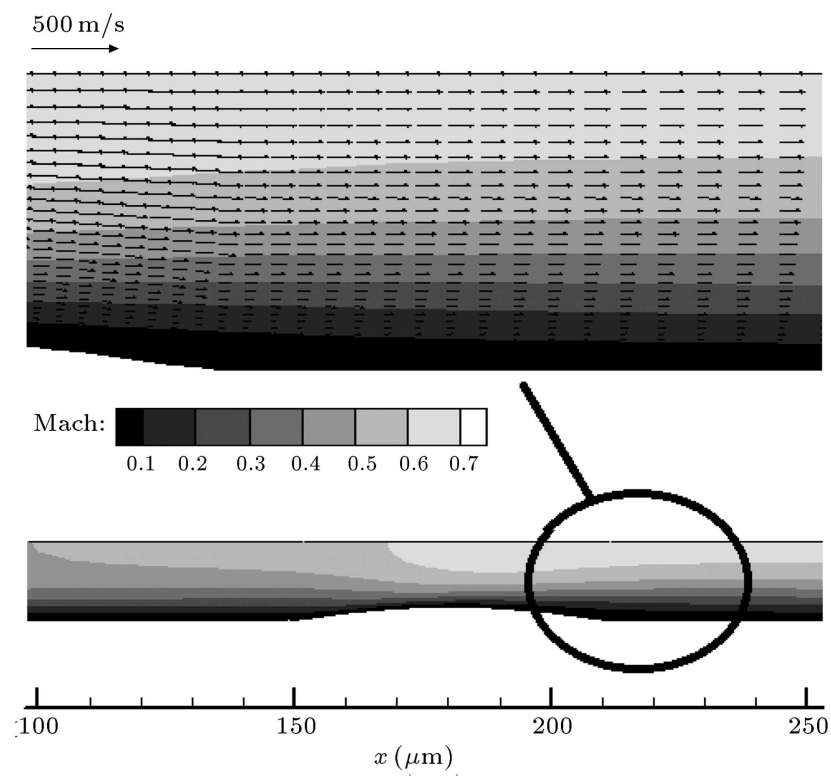

Figure 7. Mach number contours and velocity vectors around the constricted microchannel $\left(P_{\mathrm{stg}} / P_{0}=1.5\right.$, $\left.D_{t}=25 \mu \mathrm{m}, q^{\prime \prime}=10^{5} \mathrm{~W} / \mathrm{m}^{2}\right)$.

\subsection{The effect throat height}

Another important parameter in the description of gas flow in a constricted channel is the throat area. In this section, by considering a constant heat flux of $q^{\prime \prime}=10^{5} \mathrm{~W} / \mathrm{m}^{2}$ and a pressure ratio $\left(P_{\text {stg }} / P_{0}\right)$ of 1.5 , the effect of constriction height $\left(D_{t}\right)$ on hydrodynamics and thermal characteristics is investigated. At first, we compare the circulation just at the downstream of the constricted region by considering the constriction height of 5 and $25 \mu \mathrm{m}$. As seen in Figure 7 , in the case of $D_{t}=25 \mu \mathrm{m}$, the order of Mach number at the upstream is about 0.3 , and as expected, compressibility increases at the constricted channel, while the concentration of high-speed flow is widely expanded at the downstream. The velocity profiles at different cross sections are mainly uniform and no circulation (wake region) is seen after the constriction. On the other hand, as seen in Figure 8, with a constriction height of $5 \mu \mathrm{m}$, high-speed flow is concentrated at the constricted channel; the flow compressibility dramatically decreases afterwards. In this case, the high-speed flow causes a wake region after the constriction in which there is a clockwise circulation.

Distribution of Knudsen number for different constriction heights is demonstrated in Figure 9. In a plane channel, the rarefaction increases monotonically; the change of Knudsen number is not considerable. When $D_{t}=25 \mu \mathrm{m}$, rarefaction increases in comparison with a plane channel as a result of decreasing mass flow rate, but there is not an evident change of Knudsen number at constricted part. Further decrease of throat height results in sudden increment of Knudsen number in the constricted microchannel, which is caused by
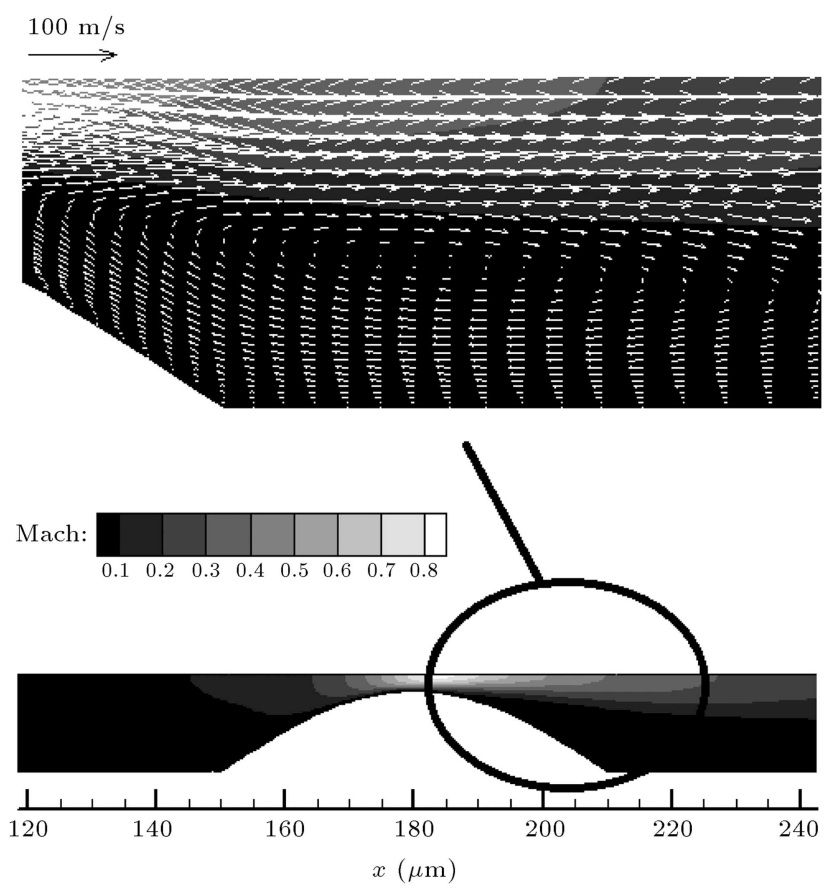

Figure 8. Mach number contours and velocity vectors around the constricted microchannel $\left(P_{\mathrm{stg}} / P_{0}=1.5\right.$, $\left.D_{t}=5 \mu \mathrm{m}, q^{\prime \prime}=10^{5} \mathrm{~W} / \mathrm{m}^{2}\right)$.

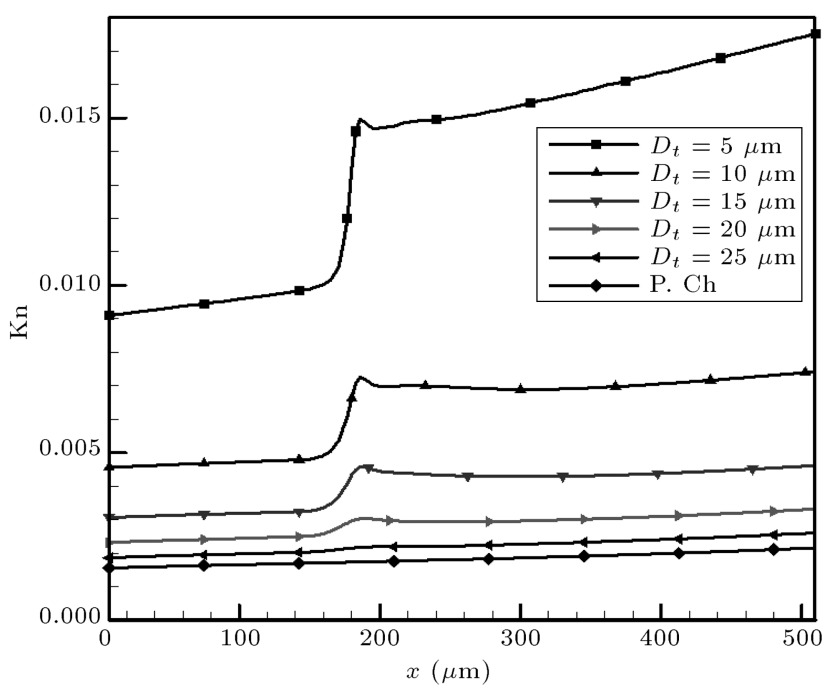

Figure 9. The effect of throat height on rarefaction $\left(P_{\text {stg }} / P_{0}=1.5, q^{\prime \prime}=10^{5} \mathrm{~W} / \mathrm{m}^{2}\right)$.

considerable decrease of pressure and density at the downstream.

The effect of throat height on compressibility (Figure 10) shows that by creating a constricted region with a height of $D_{t}=25 \mu \mathrm{m}$, in comparison with a plane channel, Mach number at the straight portions of microchannel decreases and increases in the constricted area. Further decrease of throat height results in more decrement of compressibility at the straight sections, while the trend is different at the constricted region. In this area, Mach number increases by decreasing con- 


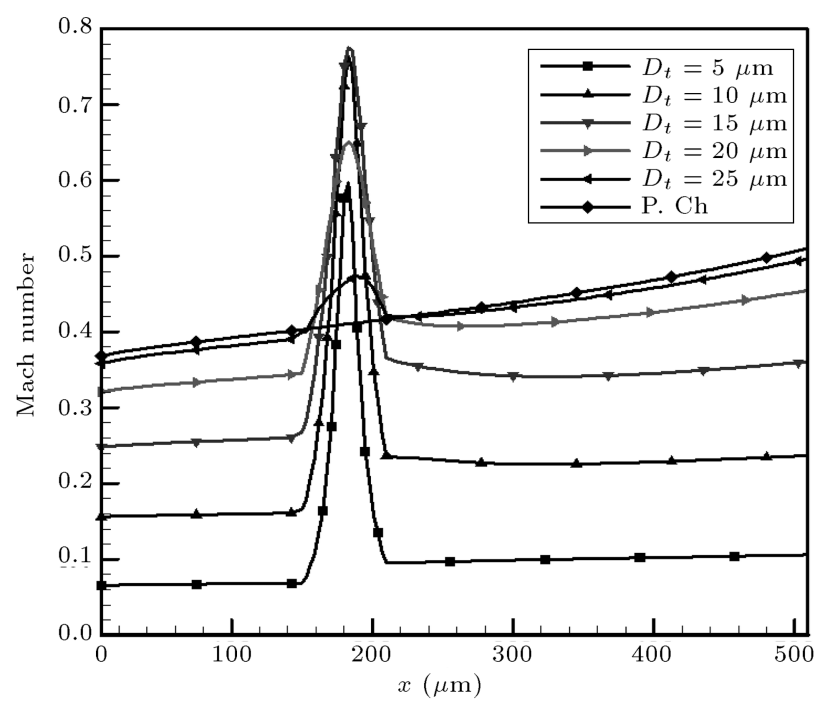

Figure 10. The effect of throat height on compressibility $\left(P_{\mathrm{stg}} / P_{0}=1.5, q^{\prime \prime}=10^{5} \mathrm{~W} / \mathrm{m}^{2}\right)$.

striction height down to $15 \mu \mathrm{m}$ and then, Mach number decreases again. Therefore, there is an optimum throat height to have the most compressibility in the constricted channel. This phenomenon can be explained by considering two major effects of decreasing throat height:

1. Increase of resistance against the fluid flow and decrease of mass flow rate;

2. Decrease of cross section at the constricted region and increase of fluid velocity in this area.

At lower throat heights, the first effect is so dominant that the Mach number will not be considerable even by less cross section at constricted portion.

Finally, the surface temperature is considered in Figure 11. Similar to compressibility, there are two effects of decreasing throat height:

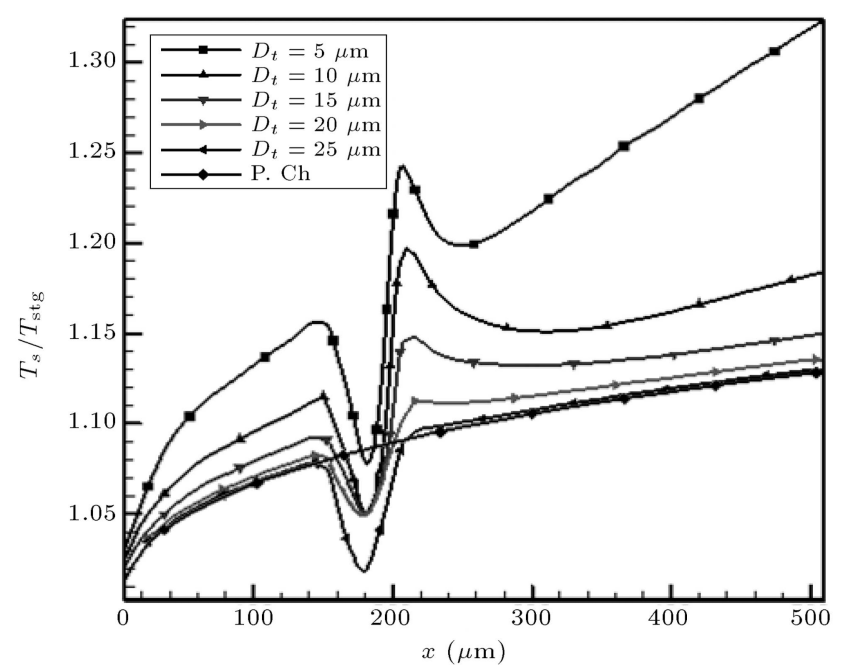

Figure 11. Microchannel's wall temperature at different throat heights.

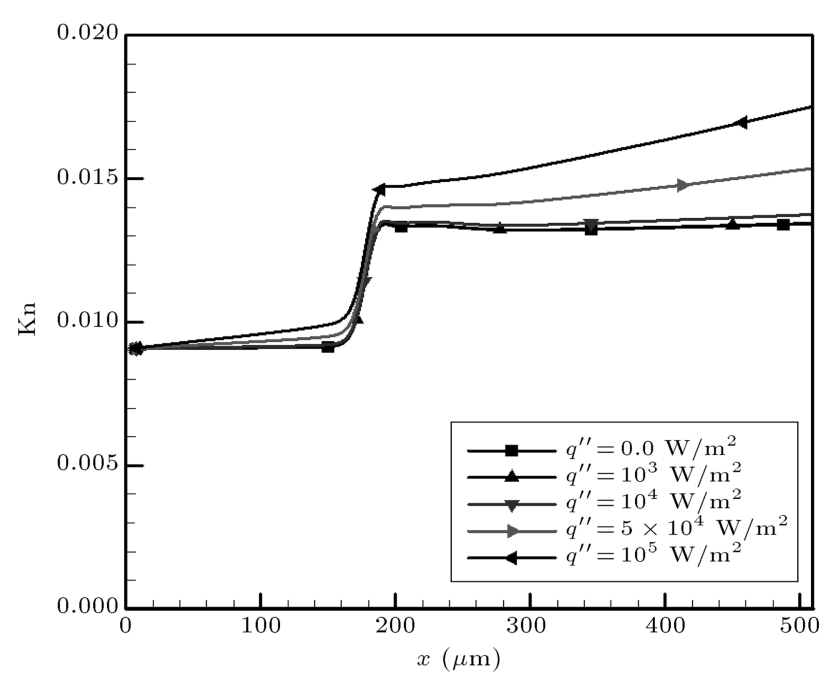

Figure 12. The effect of applied heat flux on rarefaction $\left(P_{\text {stg }} / P_{0}=1.5, D_{t}=5 \mu \mathrm{m}\right)$.

1. Decrease of mass flow rate and convective heat transfer from the walls;

2. Decrease of cross section and more conversion of thermal energy into kinetic energy at the constricted region.

By considering these two effects, the minimum surface temperature is achieved when the throat height is in the range of $25<D_{t}<30 \mu \mathrm{m}$.

\subsection{The effect of heat flux value}

Another effective parameter in fluid flow is the heat flux at the walls. In this section, $5 \mu \mathrm{m}$ throat height is considered while the pressure ratio is 1.5. According to Figure 12, the rarefaction increases as the walls are heated more. This is mainly because of thermal creep effect in which more heat transfer causes less mass flow rate and Reynolds number. On the other hand, the compressibility is not changed by increasing heat flux at the walls (Figure 13).

Figure 14 exhibits surface temperature of the microchannel. As expected, more heat flux results in a more surface temperature with higher rate of increase along $\mathrm{x}$-direction. As can be seen, just at the downstream of the constricted portion, there is a local maximum in temperature curve which is more evident at higher heat fluxes. This point is caused by the wake region and less interaction of main stream with the walls, thus less convective heat transfer.

\section{Conclusion}

Compressible air flow in a constricted microchannel is investigated numerically. After studying the fluid flow at different pressure ratios and by considering slip and no-slip models, it was found that using slip model is necessary, especially at the downstream of 


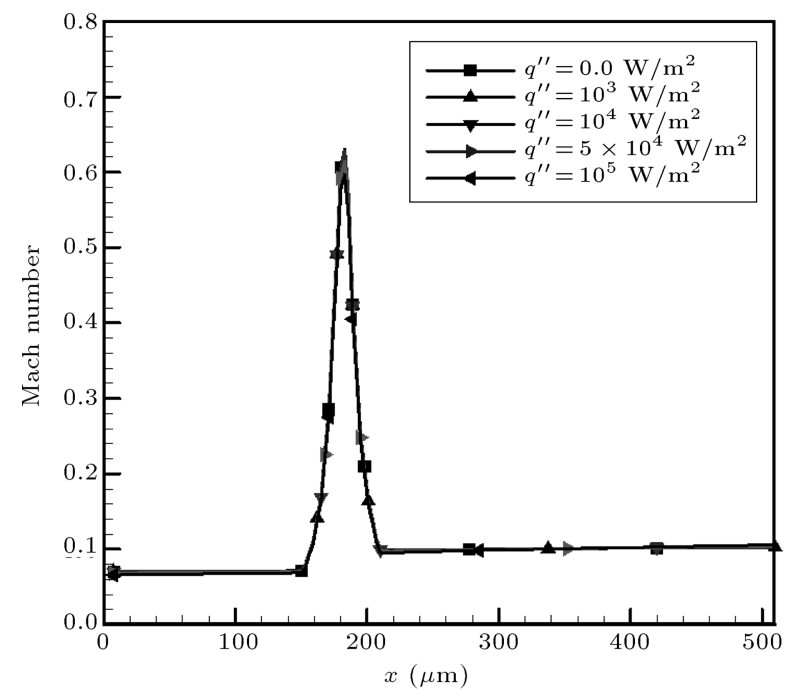

Figure 13. Distribution of Mach number along the microchannel at different heat fluxes $\left(P_{\text {stg }} / P_{0}=1.5\right.$, $\left.D_{t}=5 \mu \mathrm{m}\right)$.

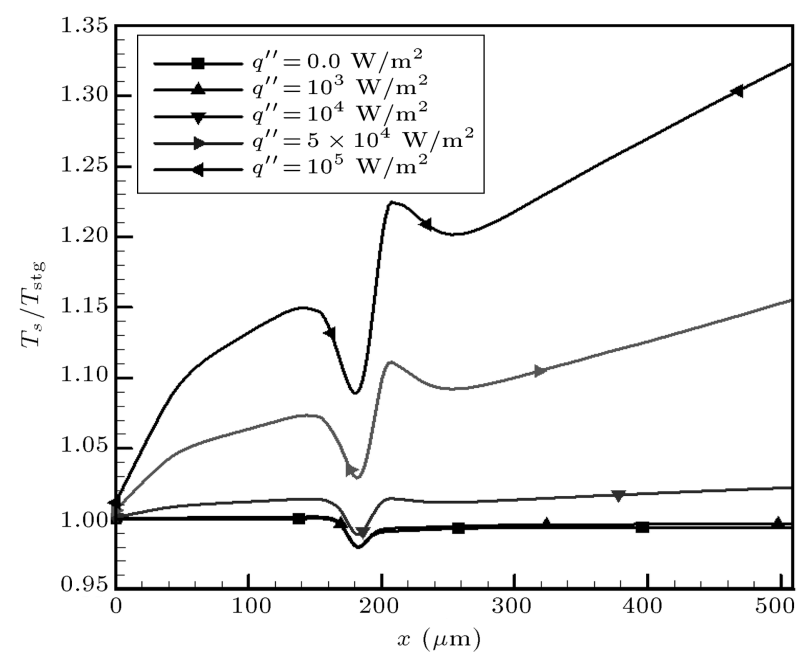

Figure 14. Surface temperature along the microchannel at different heat fluxes $\left(P_{\mathrm{stg}} / P_{0}=1.5, D_{t}=5 \mu \mathrm{m}\right)$.

the constricted portion. According to the analysis, decreasing the throat height results in a wake region at the downstream. In general, decrement in throat height results in more rarefaction and compressibility at the constricted region. Also, there is an optimum throat height in which minimum temperature is seen at the region. Furthermore, at a constant pressure ratio and throat area, more heat flux causes more rarefaction, while the compressibility is not changed.

\section{References}

1. Yu, S. and Ameel, T.A. "Slip flow convection in isoflux rectangular micro-channels", Journal of Heat Transfer, 124, pp. 346-355 (2002).

2. Asako, Y., Tianqi Pi, Turner, S.E. and Faghri, M. "Effect of compressibility on gaseous flows in micro- channels", International Journal of Heat and Mass Transfer, 9(16), pp. 3041-3050 (2003).

3. Miyamoto, M., Shi, W., Katoh, Y. and Kurima, J. "Choked flow and heat transfer of low density gas in a narrow parallel-plate channel with uniformly heating walls", International Journal of Heat and Mass Transfer, 46(14), pp. 2685-2693 (2003).

4. Hong C., Asako, Y. and Lee, J.H. "Heat transfer characteristics of gaseous flows in micro-channel with constant heat flux", International Journal of Thermal Sciences, 46(14), pp. 1153-1162 (2007).

5. Asako, Y. and Toriyama, H. "Heat transfer characteristics of gaseous flows in micro-channels", Microscale Thermophysical Engineering, 9(1), pp. 15-31 (2005).

6. Kandlikar, S., Garimella, S. and King, M.R., Heat Transfer and Fluid Flow in Minichannels and Microchannels, Elsevier, London, United Kingdom (2006).

7. Liou, W. and Fang, Y., Microfluid Mechanics, Principal and Modeling, McGraw-Hill, New York (2006).

8. Xu, J. and Zhao, C. "Two-dimensional numerical simulations of shock waves in micro convergent-divergent nozzles", Int. J. Heat Mass Transfer, 50, pp. 2434-2438 (2007).

9. Chen, C.K. and Cho, C.C. "Electro-kinetically-driven flow mixing in microchannels with wavy surface", $J$. Colloid and Interface Sci., 312, pp. 470-480 (2007).

10. Rostami, J., Abbassi, A. and Saffar-Avval, M. "Optimization of conjugate heat transfer in wavy walls micro-channels", Journal of Applied Thermal Engineering, 82, pp. 318-328 (2015).

11. Sakanova, A., Keian, C.C. and Zhao, J. "Performance improvements of micro-channel heat sink using wavy channel and nanofluids", International Journal of Heat and Mass Transfer, 89, pp. 59-74 (2015).

12. Dai, Z., Fletcher, D.F. and Haynes, B.S. "Impact of tortuous geometry on laminar flow heat transfer in microchannels", International Journal of Heat and Mass Transfer, 83, pp. 382-398 (2015).

13. Louisos, W.F., Alexeenko, A.A. and Zilić "A design considerations for supersonic micronozzles", Int. J. Manuf. Res., 3(1), pp. 80-113 (2008).

14. Lin, C.X. and Gadepalli, V.V. "A computational study of gas flow in a De-Laval micronozzle at different throat diameters", Int. J. Numer. Meth. Fluids., 59, pp. 12031216.

15. Rij, J.V., Ameel, T. and Harman, T. "The effect of viscous dissipation and rarefaction on rectangular microchannel convective heat transfer", Int. J. Thermal Sciences, 48, pp. 271-281 (2009).

16. San, O., Bayraktar, I. and Bayraktar, T. "Size and expansion ratio analysis of micro nozzle gas flow", Int. Commun. Heat Mass Transfer, 36(5), pp. 402-411 (2009). 
17. Duryodhan, V.S., Singh, A. and Singh, S.G. "Agrawal A., Convective heat transfer in diverging and converging microchannels", International Journal of Heat and Mass Transfer, 80, pp. 424-438 (2015).

18. Darbandi, M. and Roohi, E. "Study of subsonicsupersonic gas flow through micro/nano-scalenozzles using unstructured DSMC solver", Microfluid Nanofluid, 10, pp. 321-335 (2011).

19. Shokouhmand, H. and Bigham, S. "Effects of Knudsen number and geometry on gaseous flow and heat transfer in a constricted microchannel", Heat Mass Transfer, 47, pp. 119-130 (2011).

20. Sadeghi, A., Salarieh, H., Saidi, M.H. and Mozafari, A.A. "Effects of corrugated roughness on gaseous slip flow forced convection in micro-tubes", Journal of Thermophysics and Heat Transfer, 25, pp. 262-271 (2011).

21. Baghani, M. and Sadeghi, A. "Gaseous slip flow forced convection in micro-ducts of arbitrary but constant cross section", Journal of Nanoscale and Microscale Thermophysical Engineering, 18, pp. 354-372 (2014).

22. Sadeghi, A., Baghani, M. and Saidi, M.H. "Gaseous slip flow mixed convection in vertical microducts with constant axial energy input", Journal of Heat Transfer, 136, 032501 (2014).

23. Sadeghi, A. and Saidi, M.H. "Viscous dissipation and rarefaction effects on laminar forced convection in microchannels", Journal of Heat Transfer, 132, 072401 (2014).

24. Mirmanto, M. "Heat transfer coefficient calculated using a linear pressure gradient assumption and measurement for flow boiling in microchannels", International Journal of Heat and Mass Transfer, 79, pp. 269-278 (2014).

25. Asadi, M., Xie, G. and Sunden B. "A review of heat transfer and pressure drop characteristics of single and two-phase microchannels", International Journal of Heat and Mass Transfer, 79, pp. 34-53 (2014).

26. Yari Ghale, Z. and Haghshenasfard, M. "Investigation of nanofluids heat transfer in a ribbed micro-channel heat sink using single-phase and multiphase CFD models", Journal of International Communications in Heat and Mass Transfer, 68, pp. 122-129 (2015).

27. Li, Z., Haramura, Y. and Tang, D. "Analysis on the heat transfer characteristics of a micro-channel type porous-sheets Sterling regenerator", International Journal of Thermal Sciences, 94, pp. 37-49 (2015).
28. Wang, C.Y. "Slip flow and constant flux heat transfer in isosceles triangular ducts", Journal of Thermodynamics and Heat Transfer (2015). DOI. 10.2514/1.T4666

29. Law, M. and Lee, P. "A comparative study of experimental flow boiling heat transfer and pressure characteristics in straight- and oblique-finned microchannels", International Journal of Heat and Mass Transfer, 85, pp. 797-810 (2015).

30. Kiyasatfar, M. and Pourmahmoud, N. "Laminar MHD flow and heat transfer of power-law fluids in square micro-channels", International Journal of Thermal Sciences, 99, pp. 26-35 (2016).

31. Pelevi, N. and VanderMeer, Th.H. "Heat transfer and pressure drop in micro-channels with random roughness", International Journal of Thermal Sciences, 99, pp. 125-135 (2016).

32. Heydari, M.M. "Viscoelasticity effects on hydrodynamic characteristics of electrokinetically driven flow in rectangular microchannels", International Journal of Science and Technology, 22(5), pp. 1866-1876 (October 2015).

33. Sutherland, W. "The viscosity of gases and molecular force", Philosophical Magazine, 36(223), pp. 507-531 (1983).

34. Kadoya, K., Matsunaga, N. and Nagashima, A., Viscosity and Thermal Conductivity of Dry Air in the Gaseous Phase, American Chemical Society and the American Institute of Physics for the National Bureau of Standards (1985).

35. Kurganov, A. and Tadmor, E. "New high-resolution central schemes for nonlinear conservation laws and convection-diffusion equations", Journal of Computational Physics, 160(1), pp. 241-282 (2000).

\section{Biography}

Mohammad Mahdy Heydari is a Professor of Mechanical Engineering at Malek Ashtar University of Technology, Tehran, Iran. He received his BSc from Khaje Nasireddin University of Technology, Tehran, Iran, in 1994; his MSc from Tarbiat Modares University, Tehran, Iran in 1996; and his $\mathrm{PhD}$ from Sharif University of Technology, Tehran, Iran in 2007, all in Mechanical Engineering. His research interests involve propulsion, combustion, heat transfer, and renewable energy. 